\title{
Extracorporeal shock wave lithotripsy of pancreatic stones
}

\author{
T SAUERBRUCH, J HOLL, M SACKMANN, AND G PAUMGARTNER \\ From the Medical Department II, Klinikum Grosshadern, University of Munich, Munich, Federal Republic of \\ Germany.
}

SUMMARY Extracorporeal shock wave lithotripsy of pancreatic stones was performed in eight patients with chronic pancreatitis and a dilated duct system harbouring stones 5 to $20 \mathrm{~mm}$ ( $\overline{\times} 10$ (SD) $5 \mathrm{~mm}$ ) in diameter. After endoscopic sphincterotomy of the pancreatic orifice the stones were disintegrated by shock waves under fluoroscopic control using a kidney lithotripter (Dornier HM3). The procedure was well tolerated by all but one patient, who had a mild pancreatitic attack immediately after lithotripsy. Clearance of the pancreatic duct systems from the larger stones was achieved in seven of eight patients. Half of the patients showed no improvement in the intensity and frequency of pain. The other patients had a marked amelioration of symptoms, however, both immediately and during a mean follow up interval of 11 (eight) months. A selective combined approach by endoscopy and extracorporeal shock wave lithotripsy for the treatment of pancreatic stones seems promising.

Although pancreatic lithiasis occurs in less than $1 \%$ of an unselected autopsy population,' in alcoholic chronic pancreatitis the incidence of ductal calcification reaches up to $90 \% .^{2}$ Two patterns of localisation are observed: firstly, cases where the main ducts are involved and secondly those in which only small ducts and acini are calcified. ' Solitary stones predominate when the main ducts are involved. These stones are mainly localised in the duct of Wirsung within 2 to $4 \mathrm{~cm}$ of the ampulla of Vater. ${ }^{.}$This location makes them potentially amenable to endoscopic procedures such as extraction after papillotomy of the pancreatic sphincter. Endoscopic extraction of stones or other drainage procedures may improve pain attacks of these patients. ${ }^{3-5}$ Extraction, however, may be hindered by the size of the stones in relation to the anatomy of the pancreatic ducts. Encouraged by the fact that we observed no cases of severe shock waveinduced pancreatitis when treating common bile duct stones, ${ }^{\circ}$ we tested the feasibility of extracorporeal

Address for correspondence: T Sauerbruch, MD. Medical Department II, Klinikum Grosshadern, Marchioninistrasse 15, 8000) München 70), FRG.

Accepted for publication 10 July 1989. shock wave lithotripsy (ESWL) of pancreatic stones. Our first report of a successful stone extraction after extracorporeal shock wave lithotripsy ${ }^{7}$ has been followed by a preliminary report of a larger series in Belgium. ${ }^{8}$

In the present paper we describe our experience with shock wave lithotripsy of pancreatic stones in eight patients with special emphasis on stone clearance, side effects and relief of symptoms.

\section{Methods}

PATIENTS

All patients (Table 1) had recurrent attacks of pancreatic pain and were admitted to our hospital for assessment of their suitability for lithotripsy. According to the Cambridge classification," retrograde pancreatography showed moderate or marked changes in the pancreatic ductal system. All patients had decreased exocrine pancreatic function (tubeless pancreolauryl or fluorescein dilaurate secretory function test: $9 \cdot 2$ (SD) $2 \cdot 5 \%$ ). Clinical data of the patients are shown in Tables 1 and 2. The current symptom status of the patients was assessed by telephone and a self-administered questionnaire. 
Table 1 Symptoms and radiological signs before and after ESWL

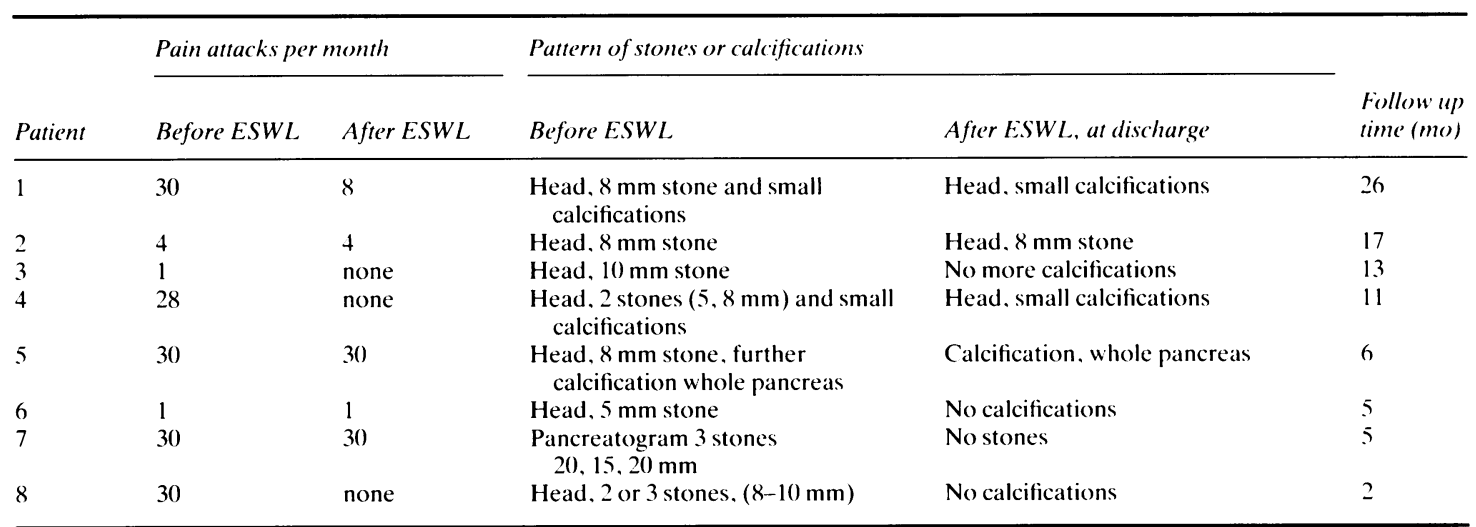

$\mathrm{ESWL}=$ extracorporeal shock wave lithotripsy.

\section{EXTRACORPOREAL SHOCK WAVE LITHOTRIPSY} OF PANCREATIC STONES

Patients were treated in supine position with slight elevation of the left shoulder (Fig. 1) in a Dornier kidney lithotripter (HM3) with a spark gap (18 kV) or an electromagnetic generator $(11-15 \mathrm{kV})$. Four patients were treated in one session, three patients in two sessions and one patient in three sessions (Table 3 ). The mean interval between the sessions was 35 (27) days. The mean number of shock wave discharges was 1356 (647) applied within 36 (10) minutes. Four treatments were performed under general anaesthesia and eight under intravenous analgesia using alfentanil.

All patients received an endoscopic sphincterotomy of the pancreatic orifice before shock wave treatment.

The radio-opaque stones were located in the shock wave focus by fluoroscopy without a nasopancreatic drainage tube in five patients. Three patients required a nasopancreatic tube for instillation of contrast medium to visualise and localise the stone during the treatment. Retreatments were done for the following reasons: failure of disintegration of the stones; insufficient disintegration of the stones, and disin-

Table 2 Characteristics of patients

\begin{tabular}{llll}
\hline & & $\begin{array}{l}\text { Time interval (yr) after diagnosis } \\
\text { Patient }\end{array}$ & $\begin{array}{l}\text { Aexiology of } \\
\text { pancreatitis }\end{array}$ \\
\hline 1 & F/33 & 3 & Unknown \\
2 & M/38 & 6 & Alcoholic \\
3 & M $/ 45$ & 5 & Alcoholic \\
4 & M/48 & 3 & Alcoholic \\
5 & M $/ 48$ & 8 & Alcoholic \\
6 & F/19 & $0 \cdot 5$ & Unknown \\
7 & M $/ 28$ & 8 & Alcoholic \\
8 & F/60 & 2 & Unknown \\
\hline
\end{tabular}

tegration of further stones that had migrated into the main pancreatic duct after previously successful extracorporeal shock wave lithotripsy.

\section{Results}

SIDE EFFECTS OF SHOCK WAVE LITHOTRIPSY

There were no major adverse effects or major

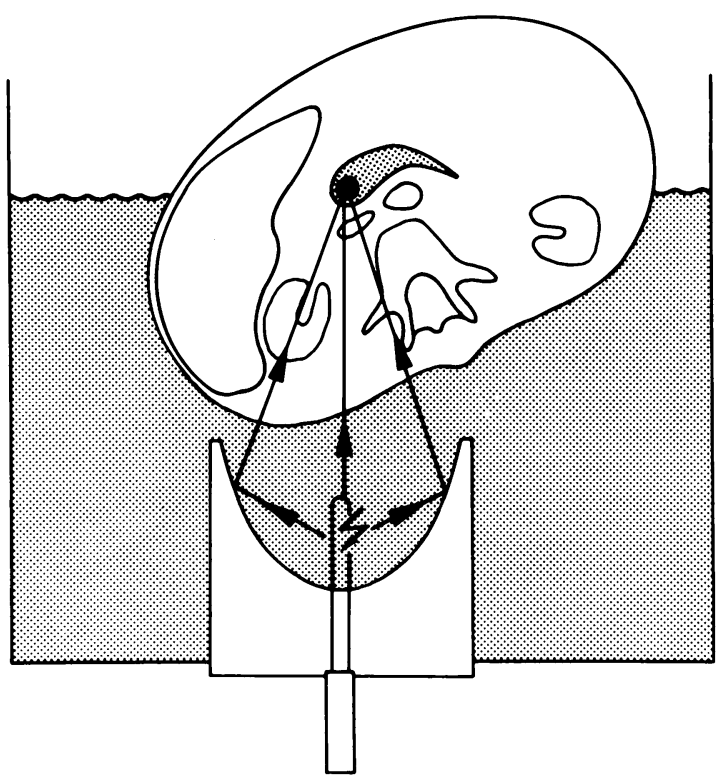

Fig. 1 Extracorporeal shock wave lithotripsy of pancreatic stones. The patient is partly immersed in the water bath of an HM3 (Dornier) in supine position. Shock waves enter the body from the rear. The shock waves are reflected by an ellipsoidal reflector to a focal area in which the stone is positioned by fluoroscopy. 
Table 3 Extracorporeal shock wave lithotripsy of the pancreatic stones

\begin{tabular}{|c|c|c|c|c|c|}
\hline \multirow[b]{2}{*}{ Patient } & \multirow[b]{2}{*}{ Shock wave source } & \multirow[b]{2}{*}{ Discharges (n) } & \multicolumn{2}{|c|}{ Serum-amylase (U/ll) } & \multirow[b]{2}{*}{ Adverse effects } \\
\hline & & & $\begin{array}{l}\text { I day } \\
\text { hefore }\end{array}$ & $\begin{array}{l}\text { I day } \\
\text { after ESWL }\end{array}$ & \\
\hline 1 & Spark-gap & $\begin{array}{l}12(0) \\
\quad \text { (one session) }\end{array}$ & 14 & 12 & $\begin{array}{l}\text { Fever, leucocytosis } \\
\text { aggravation of pain for } 3 \\
\text { days }\end{array}$ \\
\hline 2 & $\begin{array}{l}\text { Spark-gap. } \\
\text { electromagnetic }\end{array}$ & $\begin{array}{l}\text { Total } 4111 \\
\text { (three sessions) }\end{array}$ & $38 *$ & $33^{*}$ & None \\
\hline 3 & Electromagnetic & $\begin{array}{l}12(0) \\
\quad(\text { one session) }\end{array}$ & 52 & 46 & $\begin{array}{l}\text { Pain right flank during several } \\
\text { hours after ESWL }\end{array}$ \\
\hline 4 & $\begin{array}{l}\text { Spark-gap, } \\
\text { electromagnetic }\end{array}$ & $\begin{array}{l}\text { Total } 1750 \\
\quad \text { (two sessions) }\end{array}$ & $320^{*}$ & $188^{*}$ & None \\
\hline 5 & Electromagnetic & $\begin{array}{l}\text { Total } 4200) \\
\quad(\text { two sessions) }\end{array}$ & $40^{*}$ & $36^{*}$ & None \\
\hline 6 & $\begin{array}{l}\text { Spark-gap. } \\
\text { electromagnetic }\end{array}$ & $\begin{array}{l}\text { Total } 1790 \\
\quad \text { (two sessions) }\end{array}$ & $194 *$ & $181^{*}$ & $\begin{array}{l}\text { Abdominal pain one day after } \\
\text { first session }\end{array}$ \\
\hline 7 & Electromagnetic & $\begin{array}{l}20(0) \\
\quad(\text { one session) }\end{array}$ & 124 & 84 & None \\
\hline 8 & Electromagnetic & $\begin{array}{l}1200 \\
(\text { one session) }\end{array}$ & 46 & 280 & None \\
\hline
\end{tabular}

*Mean value of two or three sessions

complaints (Table 3 ). There was no increase in the mean amylase concentration $(\overline{\times} 104(105) v \overline{\times} 108(97)$ U/l) when measured the day before and after extracorporeal shock wave lithotripsy. The leucocytes count slightly increased one day after extracorporeal shock wave lithotripsy, but this increase was not statistically significant $(\overline{\times} 5888(3134)$ v $10192(5883)$ cells $/ \mu \mathrm{l})$. Two patients complained of slight flank or abdominal pain after extracorporeal shock wave lithotripsy. Only one patient (no 1, Table 3) had a raised temperature or leucocytosis and aggravation of abdominal pain together with slight peripancreatic oedema, as assessed by computed tomography within the first three days after treatment. Symptoms spontancously resolved after several days. In all other patients, repeated follow up ultrasound examinations showed no morphological changes in the pancreas itself or in the peripancreatic region.

STONE CLEARANCE

Treatment failed completely in one patient (no 2), who had an impacted stone in the head of the pancreas despite three sessions performed within one month. In the seven other patients, disintegration of the stones was achieved. Patients required endoscopic extraction of remaining fragments after extracorporeal shock wave lithotripsy for complete clearance from the ductal system. Total clearance of stones and fragments after extracorporeal shock wave lithotripsy was observed in four of the eight patients (Table 1). In three patients, large stones could be removed from the main pancreatic duct, but small calcifications persisted in the peripheral branches of the gland (Table 1).
RELIEF OF SYMPTOMS

During a mean follow up time of $11(8)$ months, three of the eight patients had complete relief from abdominal pain attacks (Table 1). In one patient (no 1) symptoms improved after treatment, four patients had no change. In two of these patients without change the cause was probably the pancreatic morphology. In one patient (no 2), the stone did not respond to the treatment at all, and in the second patient (no 6) a small calculus was successfully shattered. The fragments could not, however, pass into the duodenum because of a narrow and tight pancreatic ductal stenosis. In another patient (no 5), a solitary $8 \mathrm{~mm}$ stone was successfully treated; however, there were further calcifications distributed along the whole gland. The fourth patient (no 7, Fig. 2) in whom symptoms persisted had large stones in the main pancreatic duct which were all successfully cleared from the pancreas after extracorporeal shock wave lithotripsy. This patient was readmitted with a recurrent pancreatitic pain attack after heavy alcohol intake. The other patients with alcoholic pancreatitis had been abstinent before extracorporeal shock wave lithotripsy.

\section{Discussion}

According to Sarles ${ }^{10}$ calcifying pancreatitis is accompanied by the formation of protein plugs. A decrease in a 'pancreatic stone protein' in the pancreatic juice acting as a calcium stabiliser is thought to play an important role. These plugs may act as a nucleus for calcium carbonate precipitation, leading to stone formation and impaction with 


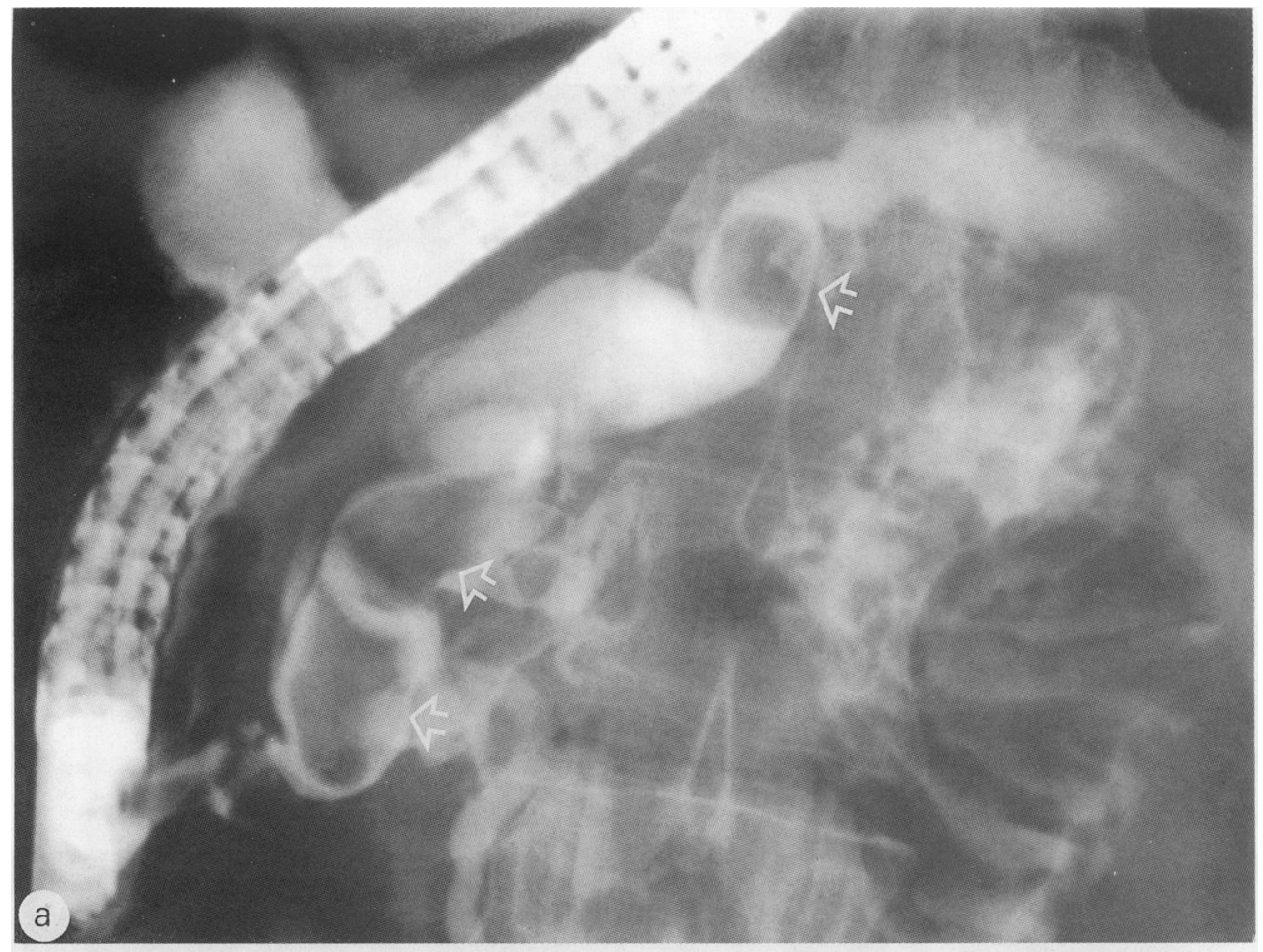

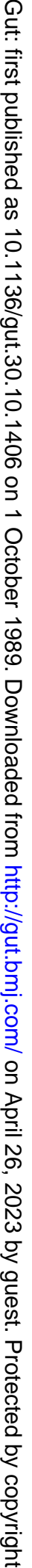

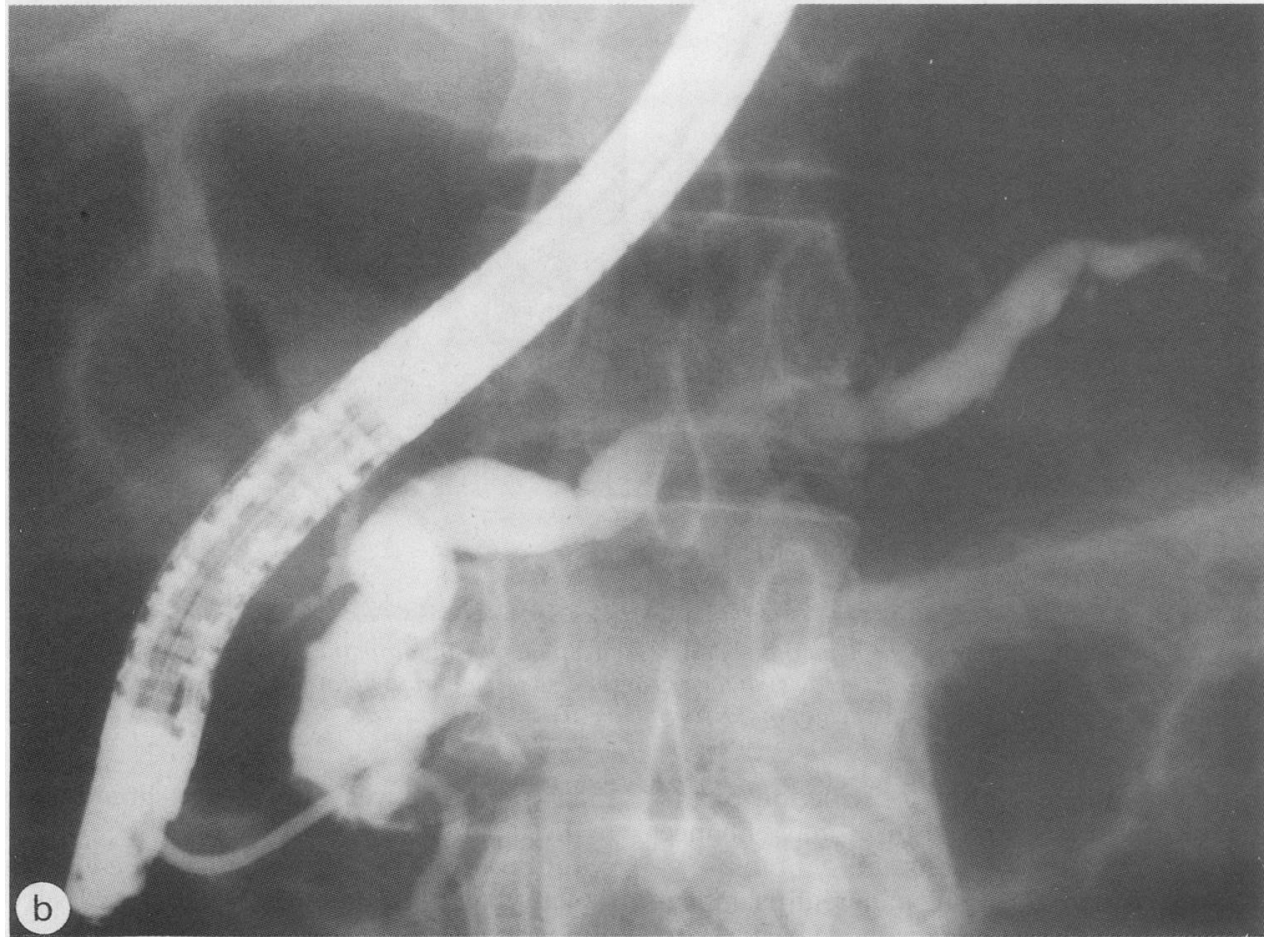

Fig. 2 Three large stones (arrows) in the pancreatic duct in a patient (no 7) with chronic alcohol pancreatitis before (a) and after extracorporeal shock wave lithotripsy, with subsequent endoscopic extraction of the fragments (b). 

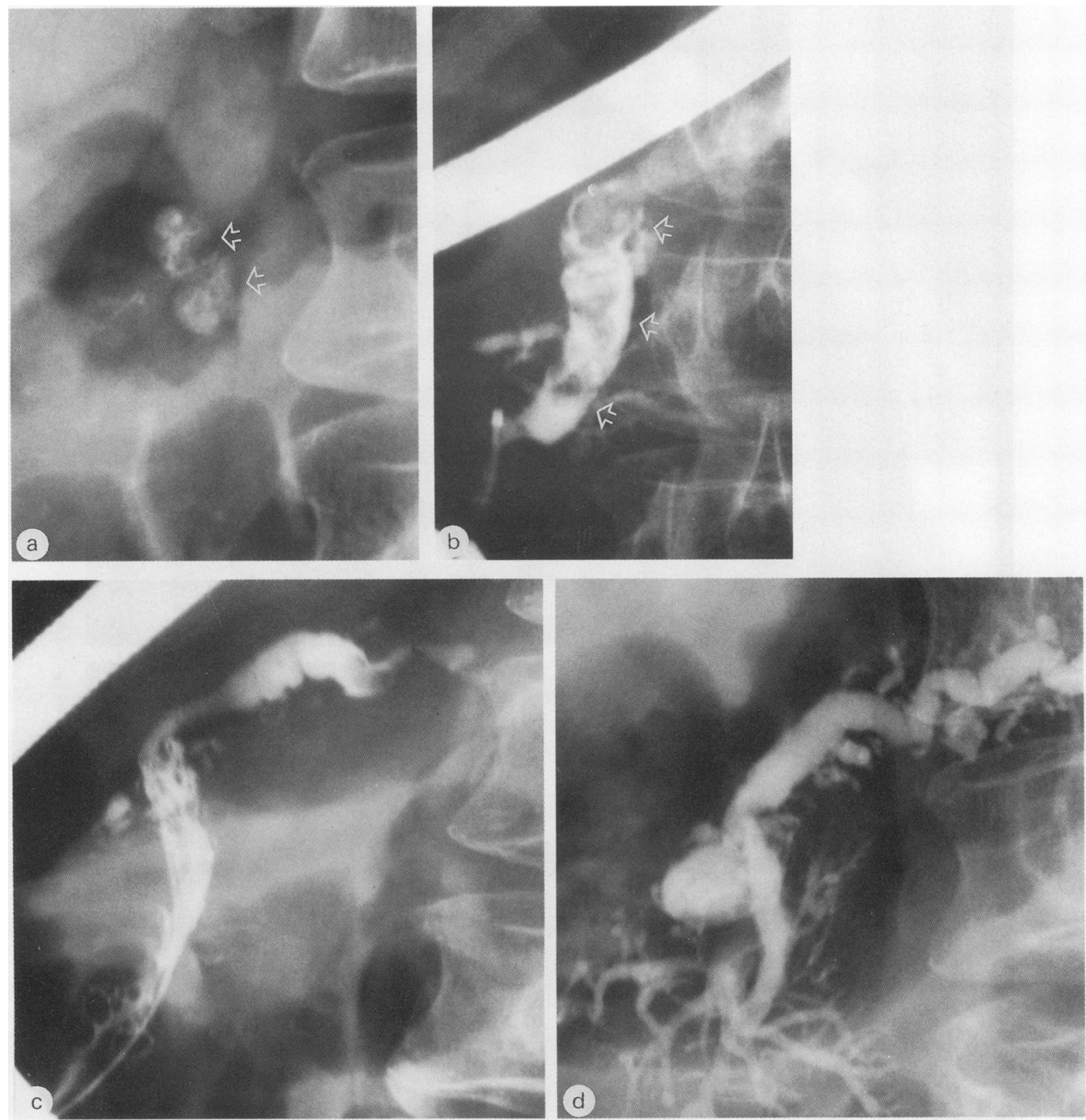

Fig. 3 Two to three calcified stones in the head of the pancreas in a patient with idiopathic chronic pancreatitis: (a) stones shown in the plain abdominal film, stones (arrows) in the retrograde pancreatogram before (b), after ESWL and disintegration (c) and after endoscopic extraction of the fragments (d).

complete or incomplete outflow obstruction of the pancreatic juice. Obstruction, in turn, may enhance the further development of lesions and symptoms.

Patients with chronic calcifying pancreatitis undergoing surgery for intractable pain may have a decreased survival time because of early postoperative mortality" or because of a deleterious effect of surgery on longterm survival. Therefore, methods that would help to avoid surgery should be explored in these patients.

In this group of eight patients we could show that pancreatic stones can be disintegrated successfully and without major adverse effects in the majority of patients, in accordance with our results with bile duct stones ${ }^{6}$ and also those of Cremer et al. ${ }^{.}$The possibility of stone fragmentation enables the non-surgical 
clearance of stones much larger than those normally amenable to endoscopic procedures, especially when ductal strictures prevent stone removal. In three of our patients, successful extraction of the stones was accompanied by a dramatic relief of pain. This result, however, could not be predicted by the pattern of calcification and did not necessarily correlate with the success of the extracorporeal shock wave lithotripsy treatment. For example, one patient (Fig. 2) with complete clearance of fragments and stones showed no improvement.

In addition to the beneficial effect on recurrent pain attacks in some patients, it may be speculated that a drainage procedure such as sphincterotomy and extraction of a large duct stone may facilitate spontaneous regression of persisting small pancreatic calcifications. ${ }^{12}$

Our results encourage clinical trials of extracorporeal shock wave lithotripsy in patients with stones in the pancreatic duct.

This work was presented in abstract form at the meeting of the American Gastroenterological Association, Washington, 1989.

We are indebted to Ms M Bäurer for secretarial help.

\section{References}

1 Edmonson HA, Bullock WK, Mehl JW. Chronic pancreatitis and lithiasis. Am J Pathol 1949; 25: 1227-47.

2 Ammann RW, Akovbiantz A, Largiadér F, Schucler G.
Course and outcome of chronic pancreatitis. Longitudinal study of a mixed medical-surgical series of 245 patients. Gastroenterology 1984: 86: 820-8.

3 Fuji T. Amano H, Hariman K. et al. Pancreatic sphincterotomy and pancreatic endoprosthesis. Endoscopy 1985; 17: 69-72.

4 Huibregste K. Schneider B, Vrij AA, Tytgat GNJ. Endoscopic pancreatic drainage in chronic pancreatitis. Gastrointest Endosc 1988; 34: 9-15.

5 Schncider MU. Lux G. Floating pancreatic duct concrements in chronic pancreatitis. Endoscopy 1985; 17: $8-10$.

6 Sauerbruch T, Stern M, and the Study Group for ShockWave Lithotripsy of Bile Duct Stones. Fragmentation of bile duct stones by extracorporeal shock waves. Gastroentrology 1989; 96: 146-52.

7 Sauerbruch T, Holl J, Sackmann M, Werner R, Wotzka R, Paumgartner G. Disintegration of a pancreatic duct stone with extracorporeal shock waves in a patient with chronic pancreatitis. Endoscopy 1987; 19: 207-8.

8 Cremer M, Vandermeeren A, Delhaye M. Extracorporeal shock wave lithotripsy (ESWL) for pancreatic stones [Abstract]. Gastroenterology 1988; 94: A80.

9 Axon ATR, Classen M. Cotton PB, Cremer M, Freeny PC, Lees WR. Pancreatography in chronic pancreatitis; international definition. Gut 1984; 25: 1107-12.

10 Sarles H. Chronic calcifying pancreatitis. Scand J Gastroenterol 1985; 20: 651-9.

11 Levy Ph, Milan Ch, Pignon JP, Baetz A, Bernades P. Mortality factors associated with chronic pancreatitis. Gastroenterology 1989; 96: 1165-72.

12 Ammann RW, Muench R, Otto R, Buehler $\mathrm{H}$, Freiburghaus AU, Siegenthaler W. Evolution and regression of pancreatic calcification in chronic pancreatitis. Gastroenterology 1988; 95: 1018-28. 